\title{
Make the technology count
}

\author{
Nikhil A. Patil, Vinay S. Kundargi, Siddangouda B. Patil, Ashok N. Biradar, Anup S. Desai
}

Shri B. M. Patil Medical College, Hospital and Research Centre, Bijapur, 586101 Karnataka, India

Good judgment comes from experience and experience comes from bad judgment

- Rita Mae Brown

In spite of advances in imaging techniques, PCNL continues to be a blind procedure. Gallbladder puncture during PCNL has been a described complication, sometime resulting in biliary peritonitis and even mortality [1]. Very few cases concerning conservative management of gallbladder puncture during PCNL have been reported in literature to date [2]. It is important to document the solid organ injury and maintain a registry of this. Voilette and Denstedt have given a major contribution by introducing standard protocol for documentation of PCNL complications [3].

A structured apprenticeship program is required to train fellow residents [4]. Recent advances in im- aging, establishment of advanced training centres, and development of simulators have decreased the incidence of complications significantly by improving technical skills. However, complications continue to plague even the most experienced surgeons. The occurrence of complications can be decreased only by gaining more experience and by learning from past mistakes.

The two-dimensional information provided by $\mathrm{X}-$ ray/ultrasound guided tracking does not provide an assessment of calyceal depth during needle puncture [5]. Neuronavigation (i.e. stereotactic surgery) has been a promising step in the field of neurosurgery [6]. Application of stereotactic surgery in the field of endourology may help in obtaining real time imaging and 3-D localization of the pelvicalyceal system, thereby reducing the complications significantly.

\section{References}

1. Ricciardi S, Sallustio P, Troisi R. Lifethreatening Biliary Complications after Percutaneous Nephro-Lithotomy: a Case Report. Acta Chir Belg. 2007; 107: 336-337.

2. Lee $\mathrm{CL}$, Anderson JK, Monga M. Residency training in percutaneous renal access: does it affect urological practice? J Urol. 2004; 171: 592-595.

3. Voilette PD, Denstedt JD. Standardizing the reporting of percutaneous nephrolithotomy complications. Indian J Urol. 2014; 30: 84-91.

4. Nerl RB, Devaraju, Hiremath MB. Training in Percutaneous nephrolithotomy: A structured apprenticeship program. J Sci Soc. 2014; 41: 26-31.

5. Turner KJ, Joseph J, Todd AW, Walsh PV, Bramwell SP. Gall bladder puncture during percutaneous nephrolithotomy; BJU Int. 2002; 90: 351.
6. Upadhyay UM, Golby AJ. Role of pre-and intraoperative imaging and neuronavigation in neurosurgery. Expert Rev Med Devices. 2008; 5: 65-73.

Correspondence Vinay S. Kundargi vinayuro@rediffmail.com 